\title{
Exploring How Chinese Primary School Psychological Counsellors Understand and Use Therapeutic Stories
}

\author{
Xi Liu ${ }^{1,2}$ (D) Antony Williams ${ }^{1}$
}

Published online: 19 May 2018

(C) The Author(s) 2018

\begin{abstract}
Psychological counsellors in western countries have used stories and storytelling for therapeutic purposes for decades. However, the development of the profession of school counselling in China is at an early stage and little research has been done on using therapeutic stories in Chinese primary school settings. This exploratory study presents qualitative data on using therapeutic stories collected from interviews with Chinese psychological counsellors who work with primary school students. Findings from a grounded theory analysis revealed that therapeutic stories were used by the participants in various therapeutic approaches. A spectrum of therapist directiveness was developed to integrate different ways of using therapeutic stories.
\end{abstract}

Keywords School counselling · Therapeutic storytelling · Therapist directiveness · China

\section{Introduction}

Storytelling has long been regarded as a natural and effective way of communicating with children across different cultures. The utilisation of therapeutic stories in psychological counselling for children is well supported in literature, and diverse approaches of adopting this therapeutic tool have been developed based on different theoretical perspectives over decades (Aydin and Yerin 1994; Bettelheim 2010; Carlson and Arthur 1999; Cook et al. 2004; Erickson and Rossi 2012; Friedberg and Wilt 2010; Gardner 1971, 1993). There is a growing body of recent Chinese literature suggesting therapeutic storytelling is a useful tool when working therapeutically with Chinese children and young people. There is a range of case reports addressing the use of stories in psychological counselling in primary, secondary and high schools and a variety of mental health problems are covered, including behaviour

Xi Liu

xi.liu@sheffield.ac.uk

1 School of Education, The University of Sheffield, Sheffield, UK

2 Sheffield, UK 
problems (Wang 2014), loss (Zhu 2011), and loneliness (Yuan 2011). Therapeutic stories are also used by psychological counsellors working in colleges to help students with adaptation problems (Wang 2009) and poverty-related problems (Zhang 2007).

Zhao (2007) and Song (2015) adopted similar research designs to explore and evaluate the effects of using stories and storytelling with children in their master's study projects. They both randomly divided their participants, who were children with behavioural problems, into an intervention group and a control group. Zhao (2007) adopted Gardner's (1971, 1993) Mutual Storytelling Technique (MST) and delivered individual counselling to the children in the intervention group within an Adlerian framework, while Song (2015) provided the intervention group children with a series of group counselling sessions involving storytelling. In both studies, the children in the control group did not receive any psychological counselling. The researchers both determined that using stories helped to produce therapeutic changes.

Overall, a number of Chinese researchers and school psychological counsellors have devoted attention to the therapeutic use of stories, but relevant studies are still sparse. For example, there are no studies examining this therapeutic tool across the spectrum of literature. A few books and articles written by western authors that have been translated into Chinese are commonly referenced in the Chinese literature, and little critical evaluation is provided. Only a few studies focus on primary school children, and there is not enough information in existing literature on psychological counsellors' understanding and experience of using therapeutic stories.

This current study explores Chinese primary school psychological counsellors' subjective experience and viewpoints on the therapeutic use of stories and storytelling. Therapeutic storytelling is defined within this article as the process of using a predesigned therapeutic story in the practice of psychological counselling with the aim of having a therapeutic effect upon the client or clients. A related approach is the co-construction of the story, where the therapeutic story is not predesigned but developed by counsellor and client as part of the therapeutic intervention. Based on the guidelines for constructing therapeutic stories developed by Sunderland (2004), the author created four therapeutic stories for the participants to use. As suggested by Sunderland (2004), the main character of the story first employs destructive coping strategies for the problems encountered, and the coping strategies resemble those often used by children in similar situations. Such coping strategies result in crisis in the main character's life, and then other characters appear in the story and help the main character adopt " a new behaviour, way of being or coping mechanism, and [then] feels a lot better" (Sunderland 2004, p. 23). The stories involved were adapted from Chinese myths and historical tales and targeted common problems including examination anxiety, social withdrawal, separation/loss, and adapting to changes (such as transferring to a new school). For example, 'The Magical Lotus Lantern', which is a Chinese mythological tale about a half-god boy rescuing his mother who was a goddess imprisoned underneath a great mountain for marrying his mortal father, was adapted to target children's mental health problems related to separation and loss.

Based on a review of literature, it was believed that therapeutic stories could be used within a wide range of theoretical orientations and, therefore, can be regarded as a transtheoretical tool and be used to integrate various approaches (Long 2013; Prochaska and Norcross 2013; Sunderland 2004). A spectrum of therapist directiveness when using therapeutic stories is proposed in an endeavour to integrate the diverse approaches of using this therapeutic tool into a coherent framework. Cases in which the participants utilised therapeutic stories are used as 
examples to elucidate the spectrum of therapist directiveness, and the way in which existing approaches fit into the spectrum will also be discussed.

\section{Method}

Grounded theory (GT) was initially developed by Glaser and Strauss (1967). It is an inductive, qualitative research methodology that can be used to explore complex issues regarding people's lives and to construct theories in social science research. (Glaser and Strauss 1967; Strauss and Corbin 1998). Glaser (1978, p. 93) stated that "...the goal of GT is to generate a theory that accounts for a pattern of behaviour which is relevant and problematic for those involved." Theories developed are 'grounded' in data; therefore, it is not necessary to formulate a hypothesis prior to collecting data (Creswell 2007; Morse 2001). According to Ralph et al. (2015), grounded theory provides researchers with a systematic approach to investigate social or psychological processes, and it is a dynamic methodology "in that it is characterized by the contemporaneously interpreted philosophical perspectives of the researcher in response to their interaction with wider social forces." (p. 2). Glaser and Strauss (1967) adopted a postpositivist paradigm when developing GT, while Strauss and Corbin (1998) emphasised the symbolic interactionist roots of the methodology. Charmaz (2014) developed a constructivist version of GT that attends to the ways in which researchers and participants work collaboratively to co-construct a new theory. Within their approach, the coconstruction process of theory is significantly influenced by the "...past and present involvements and interactions with people, perspectives, and research practices" of the researcher (Charmaz 2014, p. 17). Given the research aim, and considering the author's own experience as a psychological counsellor and a researcher, Charmaz's (2014) constructivist grounded theory was adopted as the methodological framework for this study.

\section{Participants}

The participants were drawn from a small purposive sample that included twelve psychological counsellors who were theoretically relevant to the research topic (Yardley 2000). The participants were recruited based on a community of psychological counsellors established by a psychological counselling training school in Qingdao, a city located on the east coast of China. Initially, an invitation along with a digital poster briefly outlining the research project was distributed to the community members via email. Potential participants who showed interest received a further email containing a detailed information sheet and a consent form. All the participants had chances to make enquiries about the study and were asked to sign the consent form when they decided to take part.

At the initial stage of data collection, nine participants were recruited, but one withdrew from the study later on and four others were included as the study progressed. All the participants held the national certification of psychological counsellor and regularly provided psychological services to primary school students.

An online presentation was arranged individually for each participant to present the created stories to them and to introduce the basic concept of therapeutic storytelling. The participants were expected to find opportunities to use the stories in their professional practice, and engage in an individual semi-structured interview to reflect on their experience. The participants who did not find a chance to deliver the stories were also interviewed as they provided insights into 
this therapeutic tool based on their expertise and formal experience of using stories therapeutically (if any). For each participant, the interview was held one to three months after the online presentation and all interviews were audio recorded.

\section{Data Collection and Analysis}

In constructivist grounded theory, data collection and analysis happen simultaneously (Charmaz 2014). Figure 1 delineates the main procedures of data analysis.

The data analysis process started following the completion of the first interview. The recordings of the interviews were reviewed several times and then transcribed into English text for analysis. In Grounded Theory, it is recommended that translation should take place during analysis in order to reflect the authentic meanings of the participants' expression (Larkin et al. 2007; Nurjannah et al. 2014). Therefore, the analysis commenced when the Chinese transcripts and codes were generated into English. Charmaz (2014, p. 111) describes coding as "...categorising of segments of data with a short name that simultaneously summarises and accounts for each piece of data." Sentence by sentence coding was adopted to generate initial codes, and then focused coding was conducted by "...using the most significant and/or frequent earlier codes to sift through large amounts of data" (Charmaz 2014, p. 138).

As suggested by Glaser (2009) and Charmaz (2014), gerunds (verbs ending in 'ing') were used as codes to reflect the participants' actions and experiences. The constant comparative method was utilised to identify similarities and differences in the participants' understandings and experiences of therapeutic storytelling. This method played a pivotal role in the process of constructing conceptual categories (Charmaz 2014; Glaser and Strauss 1967). Memo-writing is also an instrumental method in constructivist grounded theory, being used to reflect on the researcher's own thoughts and ruminations on the data collected (Charmaz 2014). In the current study, the researcher kept memos throughout the different phases of data collection and analysis, covering reflective thoughts, comparisons of the data, and relevant background information. Both constant comparative analysis and keeping memos contributed to the development of the interpretations of data and led to tentative categories.

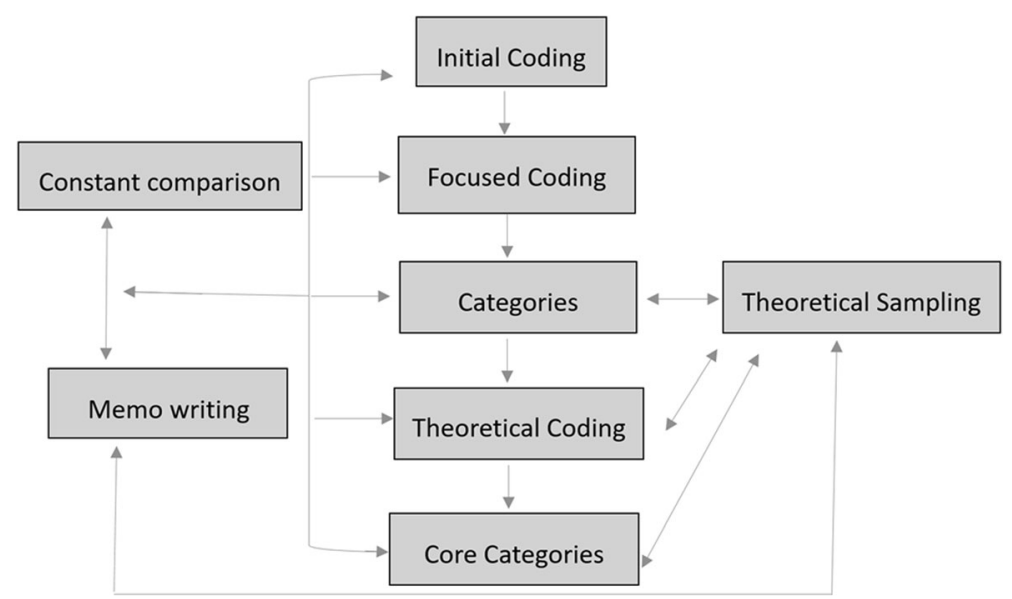

Fig. 1 Data analysis procedures in constructivist grounded theory (Charmaz 2014) 
In Constructivist Grounded Theory, theoretical sampling is a process of further data collection in order to refine and illuminate the initial categories constructed. Charmaz (2014, p. 197) stated that "initial sampling gets you started; theoretical sampling guides where you go." The researcher engaged in theoretical sampling after the seventh interview and then other participants were recruited. Through theoretical sampling and coding, tentative categories were further explored and refined, and, finally, three core categories emerged from the data. Overall, eight participants used the stories in individual psychological counselling with primary school students, and one participant used the stories in her mental health education classes. Three participants did not find an opportunity to use the stories in their practice.

According to Charmaz (2014), data collection should be an ongoing process until achieving theoretical saturation, which is a point when new categories stop emerging. However, since there are various ways to interpret data and the recruitment of participants is limited by many factors, it is difficult to claim that the point of saturation has absolutely been achieved. Dey (1999) argued that whether theoretical saturation has occurred is based on the researchers' subjective judgement, making achieving saturation more of an ideal goal rather than a realistic objective. In the current study, the data collection process stopped when interviews offered little new insights into the topic, but the occurrence of theoretical saturation remained relative.

\section{Findings}

In the exploration of how Chinese primary school psychological counsellors used therapeutic storytelling, two core categories emerged. They were 'Facilitating the therapeutic relationship' and 'Integrating therapeutic storytelling into existing therapeutic approaches and procedures'. Table 1 displays the two core categories and their main subcategories.

Some responses of the participants are translated and quoted in this section. Although English was not the first language of the participants, they all had some knowledge of English. The participants were invited to comment on the translations of their words to ensure that their original meanings were retained.

\section{Core Category 1. Facilitating the Therapeutic Relationship}

\section{Subcategory 1: Establishing a Therapeutic Alliance Through Storytelling}

In the current study, therapeutic storytelling refers to the process of telling therapeutic stories within counselling. Many participants chose to implement storytelling at the outset of the

Table 1 Core Categories and Subcategories

\begin{tabular}{ll}
\hline Core Categories & Subcategories \\
\hline Facilitating the therapeutic relationship. & - Establishing a therapeutic alliance through storytelling. \\
$\begin{array}{ll}\text { Integrating therapeutic storytelling into existing } \\
\text { therapeutic approaches and procedures. }\end{array}$ & $\begin{array}{l}\text { - Udopting storytelling as a way of communication. } \\
\text { storytelling from diverse perspectives. } \\
\end{array}$ \\
- Incorporating therapeutic storytelling as an adjunct \\
therapeutic tool.
\end{tabular}


counselling contact in an effort to engage children. It seems that primary school students' resistance to attending psychological counselling was a common problem as many of them were 'sent' by teachers and parents to see the psychological counsellor. For example:

Storytelling can draw the student's attention, and make myself more relaxed. How to explain...it's like... as long as we began to tell the story, it was not me who was talking to the student anymore. I became someone who spoke children's language, which made the communication easier. (Participant 2)

In our first session, the girl was very quiet... I thought of your stories when considering how to deal with the potential resistance... What I really wanted was to let the girl know that I would be supportive without judging or criticising. (Participant 3)

For some students in higher grades [students in Year 5 and Year 6, about 11-13 years old], such as the student in my case, there are signs of puberty...their self-awareness is developing. If they are not asking for help and you claim you can help them, they may deny everything and refuse to communicate with you. They might think 'what do you know about me?' It's like there is an opposing relationship between themselves and you, and being sent to those sessions is like to do another homework. Telling a therapeutic story could be very helpful in this kind of situation because there is no judging and threats at all - it's just a simple and relaxing activity. (Participant 7)

Some participants reported that the children they worked with enjoyed the storytelling. For example:

Storytelling was conducive to the atmosphere of counselling. After I suggested to tell a story, I saw [that] her eyes lit up immediately. (Participant 7)

The whole class was listening with earnest attention and answering my question, so I feel that storytelling is an enjoyable class activity for both the students and myself. (Participant 12)

\section{Subcategory 2: Adopting Storytelling as a Way of Communication}

Storytelling was used by many participants as a technique to enhance the effectiveness and efficacy of communication. The psychological counsellors were unanimous in supporting the notion that storytelling can facilitate reciprocal communication during counselling sessions.

Storytelling is a technique we use to communicate with children...I did find the initial communication, breaking the ice, went smoothly. (Participant 5)

I introduced [applied] the DBT [Dialectical Behaviour Therapy] training techniques to the student through giving examples with the boy in the story, and that's very helpful. (Participant 4)

There is always something children do not want to talk about, and sometimes they are unable to talk about. Therapeutic story[telling] is one of the tools we can use to assist them. (Participant 9)

Some participants advocated the use of therapeutic storytelling in combination with other activities, especially when working with children who have limited language capacities and attention spans. For example, Participant 6 used one of the stories provided within the theoretical framework of sand-tray therapy. Participant 9 also argued that: 
When working with children, especially younger children, just sitting there and talking might be not enough. It is difficult to make any progress if the child does not want to interact with you and give you any feedback. Sometimes I would draw upon some activities such as drawing, colouring, or paper folding to motivate the child to participate in the counselling. Maybe therapeutic story[telling] could also be used in combination with other techniques.

\title{
Core Category 2: Integrating Therapeutic Storytelling into Existing Therapeutic Approaches and Procedures
}

\author{
Subcategory 1: Understanding the Rationale and Impact of Therapeutic \\ Storytelling from Diverse Perspectives
}

The participants drew upon and integrated a wide range of theoretical perspectives to interpret the rationale of therapeutic storytelling, including psychodynamic, cognitive behavioural, and client-centred approaches. In spite of the diverse understandings, there was a wide consensus amongst the participants that therapeutic storytelling exerts influence on children at multiple levels.

In the process of counselling, I felt storytelling could help me to communicate better with the child, and thereby adjusting his cognition. While telling the story, I observed the child's body language - was it withdrawn or open- and the child's facial expression. These could reflect the child's real response, and open a window to his unconscious. (Participant 1)

From my experience, stories could easily influence people's emotion and cognition. (Participant 2)

Therapeutic story[telling] is like a systematic set of metaphors, therapeutic metaphors. I remember this concept is rooted in Milton Erickson's theories. (Participant 8)

I think therapeutic storytelling and some projective therapeutic tools could be used together. For example, [the] Thematic Apperception Test is all about analysing the client's stories. (Participant 9)

\section{Subcategory 2: Incorporating Therapeutic Storytelling as an Adjunct Therapeutic Tool}

All the participants who used therapeutic storytelling in their practice regarded it as an auxiliary tool to facilitate other therapeutic approaches. For example:

When conducting sand-tray therapy, basically we don't intervene after introducing how to play with the sand tray. However after exploring their stories expressed through the sand tray, it could be a good strategy to tell a story back to them. (Participant 6)

In my case, I used the House-Tree-Person test to analyse the child, and what he drew and said; it reminded me of one of your stories. That was a good chance to use therapeutic stories to help the child explore and understand his own situation. (Participant 9) 
Some participants shared their feelings about using this therapeutic technique, and it seems that they were not very familiar with therapeutic storytelling. This might be one of the reasons that none of the participants used storytelling as a major therapeutic technique.

When carrying out counselling, I never used storytelling as an official therapeutic tool. (Participant 2)

The first feeling was... a little nervous. That was because I was not familiar with therapeutic story[telling] and unconfident about using it. Consequently, I was very cautious when choosing the case to deliver the story to. (Participant 7)

\section{Subcategory 3: Adapting the Therapeutic Story to Cater to the Child}

The participants recognised the necessity for individualising the stories for each child; therefore, they tended to adopt a flexible approach when using this technique. Children's personalities, interests and developmental stage were all taken into account. Some participants suggested that children should play an active role not only in storytelling, but also in the process of developing stories.

Maybe it is more appropriate to use this tool to communicate with children who are bashful, or imaginative. (Participant 1)

Students' cognitive developmental stage is something we need to think about when deciding whether to use a story, or to use what kind of story. (Participant 6)

Therapeutic stories should be open-ended, or with multiple ending[s]. A definite positive ending could be helpful, but sometimes it also seems like a promise to children that their problems will be solved in a specific way, which we don't know whether we can keep. (Participant 7)

When we think a story is suitable for a child, will the child agree with us? Something the child is familiar with or interested in could be embedded in the story we use. (Participant 9)

\section{Discussion}

\section{Using Storytelling to Facilitate the Therapeutic Relationship}

There is a range of theoretical and empirical studies suggesting that a successful relationship between the counsellor and the client can engender therapeutic effects (Cooper 2008; Gelso and Carter 1994; Lambert and Barley 2001; Lambert and Ogles 2004; Leibert 2011; Norcross and Lambert 2011). In line with the common factors theory, the therapeutic relationship is the 'main curative component' and its effectiveness is universal across different therapeutic approaches (Lambert and Barley 2001, p. 115). Hence, the therapeutic value of storytelling can be realised through contributing to the establishment of a therapeutic relationship. Greenson (1967) developed a model of therapeutic relationships that consists of three components: the working alliance, transference/countertransference, and the real relationship. This conceptualisation of therapeutic relationships is very influential and has served as a theoretical basis for other studies in the field (Ardito and Rabellino 2011; Gabbard 2009; Gelso and Carter 1994; Hill and Knox 2009; Horvath and Luborsky 1993; Marziali and Alexander 1991). In this 
section, Greenson's (1967) model will be adopted as a framework to explore how therapeutic stories can be used to facilitate the therapeutic relationship.

The working alliance is the foundation of the relationship between a psychological counsellor and a client and conceptualises both parties' willingness to work collaboratively to achieve therapeutic outcomes (Clarkson, 2003; Dunkle and Friedlander 1996; Wills, 2008). In Chinese primary school settings, it is very common for psychological counsellors to work with students who do not take the initiative to seek professional help. As highlighted earlier, many participants used storytelling to reduce children's resistance to attending psychological counselling. Through storytelling, children may recognise that the psychological counsellor is there to help and can empathically understand their feelings, thereby relieving the sense of isolation (Cochran et al. 2010). Communication in regard to some sensitive topics can be mediated through storytelling, reducing the possibility of causing children anxiety. Therapeutic storytelling, as a non-threatening technique, also allows children to safely and openly express their feelings.

The transference/countertransference configuration can play a positive, neutral or negative role in psychological counselling (Dreikurs, 1967; Jacobs 2010; Sandler \& Sandler, 1997). According to the interviews, the transference and countertransference occurring during therapeutic storytelling can be used by the counsellor to understand the child's feelings and life experiences. For instance, Participant 9 reported that the boy he worked with said sometimes he (the counsellor) was like 'an elder family member' when telling a story. It seemed evident that the attachment between the psychological counsellor and the child was enhanced, helping the counsellor to understand the psychological status of the child (Schore, 2013). However, Participant 10 who did not use the stories provided by the author in her practice was very concerned with the potential negative effect of countertransference. She said that storytelling may induce countertransference feelings because this was a typical activity between her and her son, therefore she was especially cautious when deciding whether to use this tool.

The real relationship is another important component of Greenson's model of therapeutic relationship. It refers to the actual relationship between the child and the psychological counsellor, and 'humanistic therapists will tend to emphasise this strand of the therapeutic relationship' (McLaughlin \& Holliday, 2013, p. 102). Rogerian core conditions (empathy, congruence/genuineness and unconditional positive regard) can be drawn upon to delineate the elements involved in establishing a real relationship in psychological counselling. First, storytelling was used by the participants to demonstrate empathy, because it has an inherent quality that spontaneously facilitates empathetic understanding across individuals (Hasson et al. 2012; Zak 2015). Hasson et al. (2012, p. 5) state that “...previous studies showed that, during free viewing of a movie or listening to a story, shared external input can induce similar brain responses across different individuals." Second, in the interviews, the participants reported that they naturally delivered the stories with genuineness in order to gain the child's attention and trust. Being a genuine storyteller engenders a relaxing and comfortable counselling atmosphere. Third, the psychological counsellor can demonstrate unconditional positive regard in a vicarious way by showing support and acceptance to the main characters in a story. This strategy can be especially helpful when working with children with certain problems, such as insecure attachment relationships and low self-esteem (Burrows 2008, 2013; Campbell 2007; Perrow 2008). For example, Participant 7 reported that she commented supportively on a character's responses to challenges to normalise her client's feelings towards an examination.

Within psychological counselling using stories, a dynamic triadic relationship between the child, the story and the counsellor is created (depicted in Fig. 2). Therapeutic storytelling 


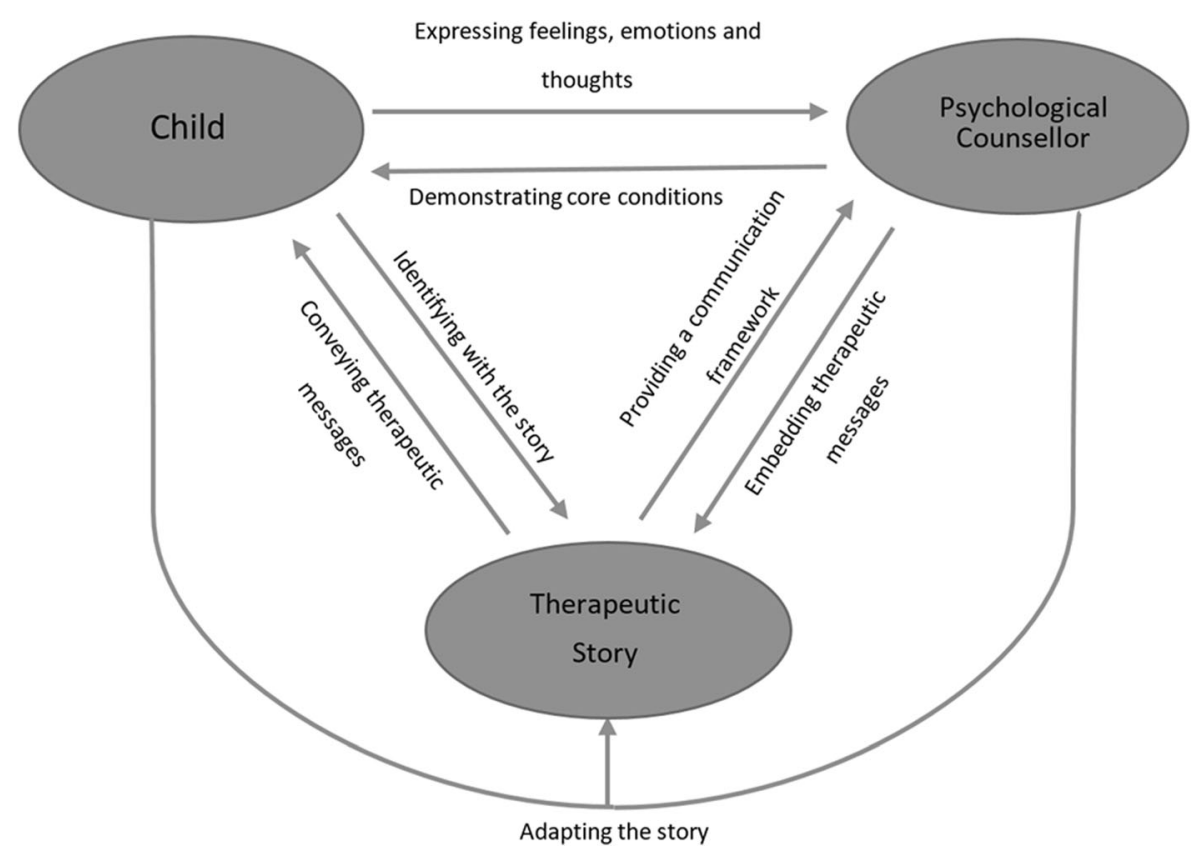

Fig. 2 The triadic relationship in therapeutic storytelling

functions as a useful tool to convey therapeutic messages, and the storytelling process enhances the communication between the child and the counsellor.

\section{The Spectrum of Therapist Directiveness When Using Therapeutic Stories}

Beutler et al. (2011, p. 135) defined therapist directiveness as "...the degree to which the therapist is the primary agent of therapeutic process or change through the selection of specific techniques and/or the adoption of a specific interpersonal demeanor." Therapeutic storytelling is a highly flexible tool compatible with a variety of therapeutic approaches (Blenkiron 2011), but the way it is utilised can be very different. Figure 3 illustrates the possible ways of using stories and storytelling therapeutically according to the level of therapist directiveness.

The spectrum is developed based on the participants' understanding and experience of using therapeutic stories. In the interviews, the participants interpreted the rationale of using therapeutic stories from different theoretical perspectives, and confirmed that this therapeutic

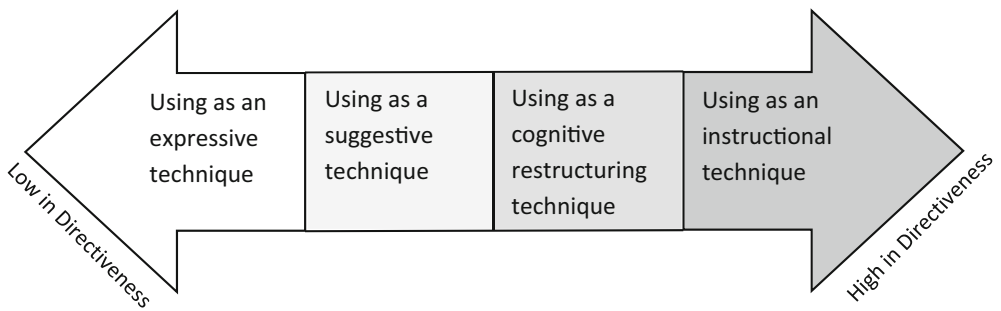

Fig. 3 The spectrum of therapist directiveness when using therapeutic stories 
tool was compatible with various therapeutic approaches, ranging from non-directive to directive. The spectrum is discussed in detail in the following section.

\section{Using Storytelling as an Expressive Technique}

Using storytelling as an expressive technique is a non-directive way of using therapeutic stories to facilitate an effective therapeutic relationship. Researchers have recognised that storytelling is an effective technique helping clients to express themselves in psychological counselling (Bradley et al. 2008; Pehrsson 2005). The theory of psychological projection underpins the function of therapeutic storytelling as an expressive technique (Schoeman and Van der Merwe 1996). From a psychodynamic perspective, the activity of storytelling is associated with two categories of projective techniques: expressive techniques and construction techniques. Construction techniques focus on what the client produces based on the stimulus, while expressive techniques also place emphasis upon the manner and style in which the product is produced. However, Milner (2004) argues that as subcategories of projective techniques, expressive techniques and construction techniques tend to overlap and merge with each other.

Storytelling is used as an expressive projective technique when children are invited to initiate the storytelling process. This utilisation of storytelling is highlighted by some therapeutic approaches in psychodynamic play therapy. For example, the mutual storytelling technique developed by Gardner $(1971,1993)$ would motivate the child to firstly tell a spontaneous story with a 'moral' to the counsellor. It is believed that this kind of story is an effective vehicle for access into children's unconscious minds. Gardner postulates that the information embedded in the stories created by children reflects the unconscious conflicts underlying their mental health problems. Based on the analysis of the story and the child's storytelling process, the psychological counsellor from this perspective would develop an adapted version of the story with a new 'moral' that incorporates therapeutic messages and deliver it to the child. Gardner's influential work provides practitioners with a systematic approach of using stories to explore children's inner worlds. However, child psychotherapists from the Kleinian school (based on the work of Melanie Klein) argue that asking children to tell a story with a moral might impose an unnecessary restriction upon children's spontaneous expression (Brandell 2016).

Storytelling is often used in combination with other techniques to assist children's expression. For example, encouraging children to draw pictures while listening to a story can help to assist their self-expression (Pomerantz 2007). Vinturella and James (1987) proposed a threephase procedure of adopting storytelling in sand-tray therapy, including introducing the sandtray and motivating the child to create a scene, encouraging the child to tell a story based on the scene, and initiating a discussion to help the child make sense of the sand scene and the story. It is contentious as to whether a counsellor should analyse and interpret the sand scene and the story and link them to the child's situation. According to Miller and Boe (1990), it is inappropriate to do so because the discussion of stories has greater therapeutic impact if it remains symbolic and metaphoric; however, Jungian psychotherapists would contest this viewpoint because they regard the interpretations provided by counsellors as helping children to reveal the underlying roots of their mental health issues (Dale and Lyddon 2000).

Using storytelling as an expressive technique is not necessarily wholly associated with psychodynamic approaches, because genuine self-exploration and open self-expression is generally encouraged in all forms of talking therapy (Malchiodi 2013). In the current study, 
although the participants did not typically ask the children to make up a story, they regarded storytelling as an effective technique in assisting children's self-expression. Therapeutic stories with certain ambiguities elicit children's individual feelings, emotions and thoughts that can be expressed through their verbal and non-verbal responses to the storyline and the characters.

Overall, therapeutic storytelling is a non-threatening technique that allows children selfexpression without pressure and anxiety. Although different specific approaches vary in many ways, it is evident that delivering a therapeutic story and encouraging the child to tell a spontaneous story can help the child to express, thus providing the counsellor with insights into the child's mental well-being. When used as an expressive technique, storytelling has both diagnostic and therapeutic value.

\section{Using Storytelling as a Suggestive Technique}

Using storytelling as a suggestive technique is best demonstrated in Milton Erickson's approach of using metaphors and stories. In contrast to classical psychoanalysts who regard the unconscious mind as a dark place storing people's repressed and unwanted feelings and thoughts, Erickson held the belief that the unconscious mind contains abundant psychological resources that can be utilised by clients to regain psychological equilibrium (Carlson 2001; Erickson and Rossi 2012). The primary aim of psychological counselling is not to offer specific advice for a problem, but to help people develop their psychological resources that enable them to deal with mental distress in a positive and constructive way (Erickson and Rossi 2012; Lankton and Lankton 1998). In the Ericksonian approach to psychological counselling, implicit suggestion is highlighted over explicit advice in terms of producing therapeutic changes (Erickson and Rossi 2012; Haley 1993). Hence, from that perspective, metaphors and stories embedded with therapeutic messages are commonly used as devices to communicate with the client at an unconscious level (Lankton 2008).

For children and young people, stories naturally speak their language and communicate with them on their own wavelength (Burns 2001; Engel 1995; Mills and Crowley 2014). Mills and Crowley (2014) maintain that stories convey information to children at both conscious and unconscious levels. The progress of a storyline draws children's conscious attention, whilst at the same time the children can unconsciously identify with the characters and connect with the therapeutic metaphors and suggestions embedded in the story. Therapeutic messages can be conveyed directly to their unconscious mind through storytelling, thus strengthening their psychological resources that help them to develop a more positive self-concept and deal with the mental challenges and difficulties encountered. Mills and Crowley (2014) describe the therapeutic storytelling process following the Ericksonian approach as “...a complex interweaving of observations, learnings, intuitions, and goals that ultimately leaves the child with a very important message." Compared to providing explicit advice, telling a story is less likely to evoke children's negative emotions and resistance to the messages received (Lankton 2008). However, it is still difficult to guarantee that the implicit suggestions will bring about therapeutic changes to children; sometimes the impact of a suggestion can be neutral or even negative (Erickson and Rossi 2012).

It is imperative for psychological counsellors to choose, adapt, create and deliver the story appropriately in accordance with the child's individual personality, needs, and developmental stage. Erickson and Rossi (2012) point out that people's active self-exploration of their problems significantly contributes to generating therapeutic changes. In psychological counselling following the Ericksonian approach, children are encouraged to play an active 
role in the storytelling. Cook et al. (2004, p. 243) noted that in the storytelling process "...the child is not passive, but actively participates in the story by asking or answering questions, telling parts of the story, providing the ending, or retelling the story to parents." Therefore, it is not recommended that children be offered a very detailed interpretation of the story (Haley 1993). Children should be empowered to perceive and comprehend the messages in therapeutic stories from their own perspectives. The therapeutic suggestions do not need to be processed consciously because they could have a positive impact on the unconscious mind and make children feel increasingly confident in improving their mental well-being.

Researchers have developed a range of therapeutic storytelling approaches based on Erickson's seminal work (e.g., Barker 2013; Burns 2001, 2007; Crenshaw 2007; Lankton \& Lankton, 1986; Mills and Crowley 2014). In China, Erickson's approach of using stories therapeutically is also widely acknowledged by researchers and practitioners. In the interviews, Participants 3 and 8 specifically referenced Milton Erickson's work when discussing the rationale of using stories therapeutically.

\section{Using Storytelling as a Cognitive Restructuring Technique}

Storytelling is also recognised as a useful technique in Cognitive Behavioural Therapy (CBT), which integrates behaviourist and cognitive theories to help people realise and change their maladaptive ways of thinking and behaving (Beck 2011). There is a large body of literature supporting CBT as an effective approach in dealing with many mental health problems, such as depression and anxiety, and it is amongst the most popular therapeutic approaches worldwide, including in China (Butler et al. 2006; Cristea et al. 2013; Guo and Hanley 2015).

The core belief of CBT is that people's distorted emotions and behaviours are not directly engendered by their life events, but caused by their problematic cognitions towards the events. The aim of CBT is to help the individual to modify dysfunctional cognitions and behaviours and develop a more adaptive and healthier way to interpret life experiences (Beck 2011). The notion of therapeutic stories impacting upon the unconscious seems at first sight not to be compatible with CBT, aiming as it does to help children develop more adaptive coping strategies (Ronen 2011). Nevertheless, therapeutic stories can be used to assist children in their cognitive restructuring process, and there is substantive empirical evidence supporting the argument that this technique is useful (e.g., Cook et al. 2004; Deblinger et al. 2006; Friedberg 1994; Friedberg and Wilt 2010; Painter et al. 1999).

CBT is a relatively directive therapeutic approach; therefore, the utilisation of stories within this framework tend to be more concrete and straightforward. For example, in Cook and colleagues 'Therapeutic Storytelling Technique' (TST), the protagonist of the story will be similar to the child, and would be going through a life predicament and mental distress that resembles the child's situation (Cook et al. 2004). After a period of exploration, eventually the protagonist will develop his/her understanding of the difficulties and find an appropriate strategy to cope with them. Through discussing the story, the counsellor is expected to help the child recognise and understand the character's maladaptive cognitions, and how changes can be made. It is believed that as counsellors, "... if we can use stories to engage people in similar emotional shifts during CBT, then we can inspire them to begin to change" (Blenkiron, 2010, p. 37).

The implementation of CBT significantly relies on the counsellor's explanation of its rationale to help induce positive cognitive change; therefore, metaphors and stories can potentially be used at any point where explanation is needed. For instance, Friedberg and 
Wilt (2010, p. 105) described a metaphor called 'Thought Shop' to expound inaccurate automatic cognitions that can occur but need to be changed.

Negative automatic thoughts are explained as clothes that looked really good and fitted well at first glance in the store after trying them on in the dressing room.

However, after you take them home and look at them in a different light, they do not fit nearly so well. Therefore, after further review, they must be exchanged.

In the current study, five of the participants utilised CBT theories and techniques in the cases they reported, and storytelling was mainly used as a cognitive restructuring technique. For example, Participant 7, who adopted REBT to help a boy in the fifth grade with test anxiety, explicitly indicated in the interview that the story was delivered and discussed in regard to addressing the boy's irrational thinking.

To sum up, therapeutic storytelling creates a space whereby the child's maladaptive thinking and behaviour pattern can be examined and challenged, while avoiding making the process crude and threatening (Schnall et al. 2016). As such, it helps to effectively and efficiently engage children in cognitive restructuring whereby alternative and healthier thoughts and coping strategies are presented, examined and practiced.

\section{Using Storytelling as an Instructional Technique}

Sometimes teaching is involved in individual and group psychological counselling. For example, it is very common for CBT practitioners to teach children some behavioural techniques. Instead of providing instructions directly, the counsellor can introduce the technique in the form of storytelling because this communication strategy facilitates a mutual understanding between the counsellor and the child, and provides the child with an imaginative learning opportunity.

In the current study, Participant 4 utilised a story to help the child learn and practice relaxation techniques that are commonly used in CBT to address anxiety and stress management problems (Feldman et al. 2007; Pretzer and Beck 2007). The techniques were demonstrated by the characters in the story, and the counsellor encouraged the child to follow and imitate them. Pardeck and Pardeck (1993) advocated this application of stories because imitation is a very basic and effective way of learning. For psychological counsellors working in Chinese school settings, teaching mental health education classes is part of their responsibilities. Participant 12 used the stories provided to support her teaching, and reported that the storytelling was 'enjoyable' for both the students and herself. It can be seen that although the therapeutic stories were not developed directly for educational purposes, they have the potential to benefit the learning of students because working through stories is an effective and appealing way of learning about life issues.

\section{Summary}

Overall, different approaches to using therapeutic stories serve various functions and can be classified according to the degree of therapist directiveness. Using therapeutic storytelling as an instructional technique is the most directive approach because it involves specific learning goals, and the process is mainly directed by the counsellor. Using therapeutic storytelling as a cognitive restructuring technique is relatively 
directive, since children are still guided by the counsellor to recognise distortions and restructure cognitions through listening to and discussing the stories. When using therapeutic storytelling as a suggestive technique, the storytelling process is more non-directive because facilitating the development of children's psychological resources becomes the primary aim and there is no specific advice offered. When storytelling is used as an expressive technique, the child plays a more active role and is often encouraged to make up a story. This manner is very non-directive because no matter whether the storytelling is initiated by the child or the counsellor, the main task of the counsellor is to observe, facilitate and analyse instead of telling the child what to do. All the approaches for therapeutic storytelling have in common is that they facilitate the development of a therapeutic relationship towards helping towards constructive change, albeit in quite different ways.

\section{Limitations}

The current study has some limitations that need to be indicated. First, the study findings are based on a small purposive sample, which means they cannot be easily generalised. The participants were all from a city located at the east coast of China; therefore, the regional differences in school psychological services are not reflected. School psychological counsellors from other areas of China may tend to use therapeutic storytelling differently and offer disparate subjective experiences. Future research may involve more school psychology practitioners across the country. The current study also only explored psychological counsellors' subjective understanding and experience of using therapeutic stories; it is, therefore, suggested that future studies may consider investigating the experiences of the children themselves who are involved in the therapeutic storytelling experience. Moreover, further research using randomised controlled trials could be conducted in an endeavour to better determine the effectiveness of using therapeutic stories in Chinese school settings.

\section{Conclusion}

In China, School psychological counselling is a young profession that faces many challenges brought about by the rapid social-economic development. There is a need for establishing a more robust school psychological service system to support the development of children and adolescents (Leuwerke and Shi 2010). The continuous professional development of school psychological counsellors, such as learning and practicing new therapeutic techniques, is important and vital to the process.

Therapeutic storytelling, as a transtheoretical therapeutic tool that is compatible with a broad range of therapeutic approaches, has been reported as being helpful in the practice of school-based psychological counselling. The participants in the current study demonstrated a tendency to integrate different psychotherapeutic approaches when understanding and using therapeutic stories. A spectrum of therapist directiveness when using therapeutic stories was developed based on the participants' responses and relevant literature, and can be adopted as a theoretical framework to support psychological counsellors' future utilisation of this therapeutic tool. 


\section{Compliance with Ethical Standards}

Ethical Approval All procedures performed in studies involving human participants were in accordance with the ethical standards of the institutional and/or national research committee and with the 1964 Helsinki declaration and its later amendments or comparable ethical standards.

Informed Consent Informed consent was obtained from all individual participants included in the study.

Open Access This article is distributed under the terms of the Creative Commons Attribution 4.0 International License (http://creativecommons.org/licenses/by/4.0/), which permits unrestricted use, distribution, and reproduction in any medium, provided you give appropriate credit to the original author(s) and the source, provide a link to the Creative Commons license, and indicate if changes were made.

\section{References}

Ardito, R. B., \& Rabellino, D. (2011). Therapeutic alliance and outcome of psychotherapy: Historical excursus, measurements, and prospects for research. Frontiers in Psychology, 2, 270.

Aydin, G., \& Yerin, O. (1994). The effect of a story-based cognitive behavior modification procedure on reducing children's test anxiety before and after cancellation of an important examination. International Journal for the Advancement of Counselling, 17(2), 149-161.

Barker, P. (2013). Using metaphors in psychotherapy. London: Routledge.

Beck, J. S. (2011). Cognitive behavior therapy: Basics and beyond (2nd ed.). New York: Guilford.

Bettelheim, B. (2010). The uses of enchantment: The meaning and importance of fairy tales. New York: Vintage Books.

Beutler, L. E., Harwood, T. M., Michelson, A., Song, X., \& Holman, J. (2011). Resistance/reactance level. Journal of Clinical Psychology, 67(2), 133-142.

Blenkiron, P. (2010). Stories and analogies in cognitive behaviour therapy. Chichester: Wiley-Blackwell.

Blenkiron, P. (2011). Stories and analogies in cognitive behaviour therapy. Hoboken: Wiley.

Bradley, L. J., Whiting, P., Hendricks, B., Parr, G., \& Jones Jr., E. G. (2008). The use of expressive techniques in counseling. Journal of Creativity in Mental Health, 3(1), 44-59.

Brandell, J. R. (2016). Of mice and metaphors: therapeutic storytelling with children. London: Sage.

Burns, G. (2001). 101 healing stories: Using metaphors in therapy. Hoboken: Wiley.

Burns, G. (2007). Healing with stories: Your casebook collection for using therapeutic metaphors. Hoboken: Wiley.

Burrows, L. (2008). Max and the knight: How a therapeutic story provided a connection point for child, family, school, human service agencies and community. In D. Bottrell \& G. Meagher (Eds.), Communities and change: Selected papers (pp. 137-149). Sydney: Sydney University Press.

Burrows, L. (2013). Transforming 'The Red Beast' within through mindfulness and therapeutic storytelling: A case study. Australian Journal of Guidance and Counselling, 23(02), 172-184.

Butler, A. C., Chapman, J. E., Forman, E. M., \& Beck, A. T. (2006). The empirical status of cognitive-behavioral therapy: A review of meta-analyses. Clinical Psychology Review, 26, 17-31.

Campbell, M. (2007). Innovative counselling with anxious children. Counselling, Psychotherapy, and Health, 3(1), 59-70.

Carlson, R. (2001). Therapeutic use of story in therapy with children. Guidance \& Counseling, 16, 92-99.

Carlson, R., \& Arthur, N. (1999). Play therapy and the therapeutic use of story. Canadian Journal of Counselling, $33(3), 212-226$.

Charmaz, K. (2014). Constructing grounded theory. London: Sage.

Clarkson, P. (2003). The therapeutic relationship (2nd ed.). London: Whurr.

Cochran, N. H., Nordling, W. J., \& Cochran, J. L. (2010). Child-centered play therapy: A practical guide to developing therapeutic relationships with children. Hoboken: Wiley.

Cook, J. W., Taylor, L. A., \& Silverman, P. (2004). The application of therapeutic storytelling techniques with preadolescent children: A clinical description with illustrative case study. Cognitive and Behavioral Practice, 11(2), 243-248.

Cooper, M. (2008). Essential research findings in counselling and psychotherapy. London: Sage.

Crenshaw, D. A. (2007). Evocative strategies in child and adolescent psychotherapy. Northvale: J. Aronson.

Creswell, J. (2007). Qualitative inquiry and research design. London: Sage.

Cristea, I. A., Montgomery, G. H., Szamoskozi, Ș., \& David, D. (2013). Key constructs in 'classical' and 'new wave' cognitive behavioral psychotherapies: Relationships among each other and with emotional distress. Journal of Clinical Psychology, 69, 584-599. 
Dale, M. A., \& Lyddon, W. J. (2000). Sandplay: A constructivist strategy for assessment and change. Journal of Constructivist Psychology, 13, 135-154.

Deblinger, E., Thakkar-Kolar, R., \& Ryan, E. (2006). Trauma in childhood. In V.M. Follette \& J.I. Ruzek (Eds.), Cognitive behavioral therapies for trauma (2nd ed., pp.405-432). New York: Guilford.

Dey, I. (1999). Grounding grounded theory: guidelines for qualitative inquiry (Vol. 282). San Diego: Academic Press.

Dreikurs, R. (1967). The individual psychological approach. In B. B. Wolman (Ed.), Handbook of child psychoanalysis: Research, theory and practice (p. 15). New York: Van Nostrand Reinhold.

Dunkle, J. H., \& Friedlander, M. L. (1996). Contribution of therapist experience and personal characteristics to the working alliance. Journal of Counseling Psychology, 43(4), 456.

Engel, S. (1995). The stories children tell: Making sense of the narratives of childhood. New York: W H Freeman/Times Books/Henry Holt \& Co..

Erickson, M. H., \& Rossi, E. L. (2012). The February man: Evolving consciousness and identity in hypnotherapy. London: Routledge.

Feldman, J.M., Eisenberg, E.J., Gambini-Suárez, E., \& Nassau, J.H. (2007). Differential effects of stress management therapies on emotional and behavioral disorders. In P.M. Lehrer \& R.L. Woolfolk (Eds.), Principles and Practice of Stress Management (3rd ed., pp. 638-681). New York: Guilford.

Friedberg, R. D. (1994). Storytelling and cognitive therapy with children. Journal of Cognitive Psychotherapy, 8(3), 209-217.

Friedberg, R. D., \& Wilt, L. H. (2010). Metaphors and stories in cognitive behavioral therapy with children. Journal of Rational-Emotive \& Cognitive-Behavior Therapy, 28(2), 100-113.

Gabbard, G. O. (2009). Textbook of psychotherapeutic treatments. Washington, DC: American Psychiatric Pub.

Gardner, R. A. (1971). Therapeutic communication with children: The mutual storytelling technique. Northvale: J. Aronson.

Gardner, R. A. (1993). Storytelling in psychotherapy with children. Northvale: J. Aronson.

Gelso, C. J., \& Carter, J. A. (1994). Components of the psychotherapy relationship: their interaction and unfolding during treatment. Journal of Counseling Psychology, 41, 296-306.

Glaser, B. G. (1978). Theoretical sensitivity: Advances in the methodology of grounded theory. Mill Valley: Sociology Press.

Glaser, B. G. (2009). Basics of grounded theory analysis: Emergence vs forcing. Mill Valley: Sociology Press.

Glaser, B., \& Strauss, A. (1967). The discovery of grounded theory (pp. 1-19). London: Weidenfield \& Nicolson.

Greenson, R. R. (1967). The technique and practice of psychoanalysis. (Vol.1). New York: International Universities Press.

Guo, F., \& Hanley, T. (2015). Adapting cognitive behavioral therapy to meet the needs of Chinese clients: Opportunities and challenges. PsyCh journal, 4(2), 55-65.

Haley, J. (1993). Jay Haley on Milton H. Erickson. Bristol: Brunner Mazel.

Hasson, U., Ghazanfar, A. A., Galantucci, B., Garrod, S., \& Keysers, C. (2012). Brain-to-brain coupling: a mechanism for creating and sharing a social world. Trends in Cognitive Sciences, 16(2), 114-121.

Hill, C. E., \& Knox, S. (2009). Processing the therapeutic relationship. Psychotherapy Research, 19(1), 13-29.

Horvath, A. O., \& Luborsky, L. (1993). The role of the therapeutic alliance in psychotherapy. Journal of Consulting and Clinical Psychology, 61(4), 561.

Jacobs, M. (2010). Psychodynamic counselling in action (4th ed.). London: Sage.

Lambert, M. J., \& Barley, D. E. (2001). Research summary on the therapeutic relationship and psychotherapy outcome. Psychotherapy: Theory, Research, Practice, Training, 38(4), 357-361.

Lambert, M. J., \& Ogles, B. M. (2004). The efficacy and effectiveness of psychotherapy. In M. J. Lambert (Ed.), Bergin \& Garfield. Handbook of Psychotherapy and Behaviour Change (5th ed., pp. 139-194). Hoboken: Wiley.

Lankton, S. (2008). An Ericksonian approach to clinical hypnosis. In M. R. Nash \& A. J. Barnier (Eds.), The Oxford handbook of hypnosis: Theory, Research, and Practice (pp. 476-485). New York: Oxford University Press.

Lankton, S., \& Lankton, C. (1986). Enchantment and intervention in family therapy: A training seminar on Ericksonian approaches. New York: Brunner Mazel.

Lankton, S., \& Lankton, C. (1998). Ericksonian emergent epistemologies: Embracing a new paradigm. In M. F. Hoyt (Ed.), The handbook of constructive therapies (pp. 116-136). San Francisco: Jossey-Bass.

Larkin, P. J., Dierckx de Casterlé, B., \& Schotsmans, P. (2007). Multilingual translation issues in qualitative research: Reflections on a metaphorical process. Qualitative Health Research, 17(4), 468-476.

Leibert, T. W. (2011). The dimensions of common factors in counseling. International Journal for the Advancement of Counselling, 33(2), 127-138.

Leuwerke, W., \& Shi, Q. (2010). The practice and perceptions of school counsellors: A view from urban China. International Journal for the Advancement of Counselling, 32(1), 75-89.

Long, N. H. (2013). Therapeutic Storytelling in a Pupil Referral Unit: The story of intersubjectivity. (Doctoral thesis, The University of Manchester, Manchester, UK).

Malchiodi, C. A. (Ed.). (2013). Expressive Therapies. New York: Guilford Publications. 
Marziali, E., \& Alexander, L. (1991). The power of the therapeutic relationship. American Journal of Orthopsychiatry, 61(3), 383.

McLaughlin, C. \& Holliday, C. (Eds.), (2013) Therapy with children and young people: integrative counselling in schools and other settings. London: Sage

Miller, C., \& Boe, J. (1990). Tears into diamonds: Transformation of child psychic trauma through sandplay and storytelling. The Arts in Psychotherapy, 17, 247-257.

Mills, J. C., \& Crowley, R. J. (2014). Therapeutic metaphors for children and the child within. London: Routledge.

Milner, J. S. (2004). Comprehensive handbook of psychological assessment: Personality assessment (Vol. 2). Hoboken: Wiley.

Morse, J. (2001). Situating grounded theory within qualitative inquiry. In R. Schreiber \& P. N. Stern (Eds.), Usinggrounded theory in nursing (pp. 1-16). New York: Springer.

Norcross, J. C., \& Lambert, M. J. (2011). Psychotherapy relationships that work II. Psychotherapy, $48(1), 4$.

Nurjannah, I., Mills, J., Park, T., \& Usher, K. (2014). Conducting a grounded theory study in a language other than English: procedures for ensuring the integrity of translation. Sage Open, 4(1), 2158244014528920.

Painter, L. T., Cook, J. W., \& Silverman, P. S. (1999). The effects of therapeutic storytelling and behavioral parent training on noncompliant behavior in young boys. Child and Family Behavior Therapy, 21(2), 47-66.

Pardeck, J. T., \& Pardeck, J. A. (1993). Bibliotherapy: A clinical approach for helping children. Langhorne: Gordon and Breach.

Pehrsson, D. E. (2005). Fictive bibliotherapy and therapeutic storytelling with children who hurt. Journal of Creativity in Mental Health, 1(3-4), 273-286.

Perrow, S. (2008). Healing stories for challenging behaviour. Gloustershire: Hawthorn Press.

Pomerantz, K. A. (2007). Helping children explore their emotional and social worlds through therapeutic stories. Educational and Child psychology, 24(1), 46.

Pretzer, J. L., \& Beck, A. T. (2007). Cognitive approaches to stress and stress management. In P. M. Lehrer, R. L. Woolfolk, \& W. E. Sime (Eds.), Principles and practice of stress management (3rd ed., pp. 465-496). New York: Guilford.

Prochaska, J. O., \& Norcross, J. C. (2013). Systems of psychotherapy: A transtheoretical analysis. Boston: Cengage.

Ralph, N., Birks, M., \& Chapman, Y. (2015). The methodological dynamism of grounded theory. International Journal of Qualitative Methods, 14(4). https://doi.org/10.1177/1609406915611576.

Ronen, T. (2011). The Positive power of imagery: Harnessing client imagination in CBT and related therapies. West Sussex: Wiley-Blackwell.

Sandler, J., \& Sandler, A.M. (1997). A psychoanalytic theory of repression and the unconscious. In J. Sandler and P. Fonagy (Eds.), Recovered memories of abuse: True or false? (pp. 163-181). London: Karnac Books.

Schnall, E., Eichenbaum, B., \& Abramovitz, Y. (2016). Jewish stories in mental health counseling. Journal of Creativity in Mental Health, 11(1), 12-26.

Schoeman, J. P., \& Van der Merwe, M. (1996). Entering the child's world: A play therapy approach. Pretoria: Kagiso Tertiary.

Schore, A.N. (2013). Affect regulation and the repair of the self. New York: Norton.

Song, X. X. (2015). Using stories to promote children's mental health (Master's Thesis, Central China Normal University, Wuhan, China).

Strauss, A., \& Corbin, J. (1998). Basics of qualitative research. London: Sage.

Sunderland, M. (2004). Using story telling as a therapeutic tool with children. Milton Keynes: Speechmark.

Vinturella, L., \& James, R. (1987). Sand play: A therapeutic medium with children. Elementary School Guidance and Counseling, 21(3), 229-238.

Wang, G. Q. (2009). Using story therapy to help new students with adaptation problems [in Chinese]. Ideological and Theoretical Education, 22, 64-67.

Wang, X. F. (2014). A case study on using metaphoric story therapy to help a student with stealing behaviour [in Chinese]. Mental Health Education in Primary, Secondary and High Schools, 6, 33-34..

Wills, F. (2008). Skills in cognitive behaviour counselling and psychotherapy. London: Sage.

Yardley, L. (2000). Dilemmas in qualitative health research. Psychology \& Health, 15(2), 215-228.

Yuan, Y. (2011) Using story therapy in group psychological counselling with lonely college students [in Chinese]. New Curriculum (Teaching and Research), 10, 106.

Zak, P. J. (2015). Why inspiring stories make us react: The neuroscience of narrative. Cerebrum: The Dana Forum on Brain Science, 2015, 2.

Zhang, L. X. (2007). Using positive psychotherapy and story therapy in group counselling with students in poverty [in Chinese]. In Proceedings of the Tenth National Conference of College Mental Health Education and Psychological Counselling.

Zhao, Y. (2007) Study on the effiectiveness of the mutual storytelling therapy on children with behavioral disorders. (Master's Thesis, East China Normal University, Shanghai, China).

Zhu, H. (2011). Using metaphoric stories in psychological interventions in colleges [in Chinese]. Weekly Magazine of Examinations, 46, 199-200. 